\title{
O impacto da padronização dos desperdícios em uma indústria de autopeças
}

A necessidade de eliminar as atividades que consomem recursos e não agregam valor leva as empresas a aplicar o trabalho padronizado resultando em ganhos significativos de produtividade. No estudo apresentado, objetivou-se investigar se as atividades padronizadas são puro valor agregado ou se uma reavaliação da técnica de trabalho padronizado no processo produtivo encontra novas oportunidades de melhoria. $\mathrm{O}$ artigo utiliza a metodologia de pesquisa-ação aplicada no processo produtivo de uma linha de montagem em uma indústria automotiva da região Sul Fluminense, onde a reavaliação do trabalho padronizado, ferramenta da filosofia Lean, identificou desperdícios padronizados dentro do processo, mensurados pelo aumento da produtividade em $29 \%$, sem afetar a estabilidade dos indicadores qualidade e segurança.

Palavras-chave: Lean Manufacturing; Trabalho Padrão; Manufatura Enxuta.

\section{The impact of waste standardization in an automobile industry}

For eliminate activities that consume resources but are not add value companies have been used the standardized work resulting in significant productivity gains. This work investigate if the standardized activities are pure added value or if a re-evaluation of the standardized work technique in the productive process finds new opportunities for improvement. The article uses the research-action methodology applied in the production process of an assembly line of an automotive industry in the South Fluminense region in Brazil, where the reassessment of standardized work, a Lean philosophy tool, identified standardized wastes within the process, measured by the increase of productivity by $29 \%$, without affecting the stability of quality and safety indicators.

Keywords: Lean Manufacturing; Standard work; Lean production.

Topic: Operações e Processos da Produção

Reviewed anonymously in the process of blind peer.
Received: $11 / 01 / 2019$

Approved: 21/04/2019
Ualison Rébula Oliveira (iD

Universidade Federal Fluminense, Brasil

http://lattes.cnpq.br/6460931837390456

http://orcid.org/0000-0002-8097-4889

ualison.oliveira@gmail.com

Oydil Cesar de Figueiredo

Universidade Federal Fluminense, Brasil

http://lattes.cnpq.br/7055034201666337 oydil@hotmail.com
Referencing this:

OLIVEIRA, U. R.; FIGUEIREDO, O. C.. O impacto da padronização dos desperdícios em uma indústria de autopeças. Revista Brasileira de Administração Científica, v.9, n.1, p.115-126, 2018. DOI: http://doi.org/10.6008/CBPC2179-684X.2018.001.0008

DOI: 10.6008/CBPC2179-684X.2018.001.0008 


\section{INTRODUÇÃO}

A necessidade crescente de células produtivas cada vez mais eficientes torna imprescindível a utilização de ferramentas de Manufatura Enxuta (ALVES et al., 2010), sendo que nesse ambiente extremamente agressivo o trabalho padronizado se destaca dentro do Lean Manufacturing como influenciador do aumento da competitividade. $\mathrm{O}$ trabalho padronizado contém uma maneira diferente de pensamento que motiva toda a organização a trabalhar de forma mais eficiente e oferece uma maior qualidade a um custo mais baixo (JOHANSSON et al., 2013). Para Rajenthirakumar et al. (2014), as instruções de trabalho padrão são usadas para manter e melhorar a produtividade, segurança e qualidade, permitindo o balanceamento de linha e otimizando o processo através da correta distribuição das atividades ao longo das estações de trabalho. Várias pesquisas sobre o trabalho padronizado validam as melhorias nesses indicadores através da sua aplicação ou pela identificação dessa oportunidade, entre elas as de Freitas et al. (2017); Ferreira et al. (2016); Neto et al. (2015); Mariz et al. (2013) e Berkenbrock et al. (2009).

Nesse contexto, usar o trabalho padronizado é algo esperado pelas empresas de classe mundial, porém, as empresas que aplicam essa técnica apresentam um processo isento de desperdícios ou há padronização de valor não agregado?. Diante dessa questão, julga-se cabível a investigação de um processo produtivo já padronizado, identificando se há oportunidades de melhoria ou se essa técnica já está em seu estado da arte. Nesse sentido esta pesquisa tem como objetivo abordar a relação entre a reanálise do trabalho padronizado e a melhoria do desempenho operacional por meio de uma pesquisa-ação com mensuração dos resultados através dos indicadores de produtividade, qualidade e segurança.

Quanto à estrutura do artigo, o mesmo está organizado como segue. Primeiramente abordam-se o referencial teórico; a seção seguinte apresenta os procedimentos metodológicos, em seguida são apresentados os resultados da pesquisa empírica e sua discussão, finalizando o trabalho, encontram-se as principais conclusões e sugestões de trabalhos futuros, seguidas das referências bibliográficas utilizadas.

\section{REVISÃO TEÓRICA}

\section{Produção Enxuta}

O Lean Manufacturing é uma filosofia nascida na Toyota que busca a eliminação das atividades que consomem recursos como, por exemplo, os estoques de matéria-prima, estoque em processo e produtos finais (DEMETER et al., 2011). A implementação de Sistemas de Produção Enxuta (SPE) é reconhecidamente essencial para as empresas que desejam obter elevado nível de competitividade (TORTORELLA et al., 2013). A motivação central da metodologia Lean Manufacturing é buscar a redução do tempo entre o pedido do cliente e a entrega por meio da eliminação de desperdícios promovendo a identificação do que agrega valor (e do que não agrega) na perspectiva do cliente (SILVA et al., 2011). Castro et al. (2012) reforçam que o Lean Thinking tem como proposta principal a geração de valor para o cliente, eliminando os desperdícios, tornando a organização mais competitiva no mercado. 
Segundo Bhamu et al. (2014), a Manufatura Enxuta proporciona às organizações uma liderança competitiva por meio da redução de custos e melhoria da produtividade e qualidade. Segundo Cançado et al. (2014), a implementação do Lean Thinking na Empresa promove uma mudança organizacional envolvendo: tecnológica, planejamento e diretrizes.

As empresas buscam padrões cada vez mais elevados de produtividade e qualidade (SILVA et al., 2011). A Produção Enxuta tem como foco o combate às perdas trazendo ganhos substanciais em qualidade, prazos de entrega e custos (SAURIN et al., 2010). Silva et al. (2011) afirmam que a aplicação de técnicas como Lean tem motivado substanciais mudanças no sistema físico de produção, mas, para se alcançar os resultados superiores vislumbrados, é imperativo que as pessoas desenvolvam novas competências para trazer novos conhecimentos, habilidades e atitudes.

A Produção Enxuta pode ser considerada como uma estratégia viável, pois nela temos planejamento de curto e de longo prazo, promovendo o desempenho superior em várias dimensões que eram consideradas conflitantes, tais como: baixo custo, alta qualidade, velocidade e flexibilidade (FILHO et al., 2016).

\section{Trabalho Padronizado}

Para Flinchbaugh (2015), a inclusão do trabalho padrão como uma prática integral da equipe de liderança elevará a chance de sucesso nos negócios. Para Marodin et al. (2013) o trabalho padronizado está ligado à identificação e alocação das atividades entre operadores da melhor forma possível, além de permitir redução dos desperdícios dos tempos de movimentação de operadores entre operações. Santos et al. (2017), entendem que o estabelecimento, de procedimentos precisos para a execução das tarefas, fornece condições para uma produção estável. Segundo Saurin et al. (2010), a utilização da padronização do trabalho é um requisito básico para garantir estabilidade no sistema produtivo.

Segundo Tortorella et al. (2017), o trabalho padronizado visa: (i) criar estabilidade básica nos processos através da eliminação das fontes de variação; (ii) balancear a carga de trabalho; e (iii) manter a qualidade através das rotinas. Liker (2005) ressalta que a definição do trabalho deve ser rígida, porém, flexível o suficiente para que possa ser inovado e assim contribuir com os objetivos de custo, qualidade e entrega. Leite et al. (2017), destacam que o balanceamento de linha permite elevar a eficiência de um processo produtivo. As instruções de trabalho devem ser fornecidas com detalhes completos, permitindo sua compressão e interpretação. (SILVA et al., 2013). O Trabalho padronizado traz flexibilidade ao processo obtido por meio da utilização de operadores com multi-habilidades (AZZAM et al., 2011), demonstrando que o trabalho padronizado pode trazer ganhos significativos na redução dos custos de manufatura e aumento da produtividade (GAUTAM et al., 2012).

As operações padronizadas resultam no estabelecimento de procedimentos para a execução das atividades, com documentação e exibição nas estações de trabalho, mantendo condições para um fluxo de produção estável (SANTOS et al., 2017). Segundo Shingo (1996), a divisão do trabalho foi o mais importante desenvolvimento que revolucionou a produtividade humana na idade moderna. Ele se referia ao conceito aplicado por Ford aonde cada operador era responsável por pequenas tarefas dentro do processo de 
montagem com peças intercambiáveis e com ganhos significativos de tempos de montagem em série, nos tempos aonde a demanda era maior que a capacidade produtiva industrial. O conceito aplicado pelo sistema Lean é um pouco diferente, pois não visa a máxima capacidade produtiva das instalações, e sim a adequação desses elementos de trabalho ao Takt. Segundo Bulhões et al. (2011), essa distribuição das atividades dos operadores em relação ao tempo Takt é composta por algumas etapas como: (i) identificação dos elementos do trabalho; (ii) eliminação do trabalho desnecessário (operações e processos que não agregam valor). Para Silva et al. (2015), o conceito de valor é abordado por diversas perspectivas, além de construir uma realidade mais coerente e útil do ponto de vista estratégico.

\section{Takt}

O Takt time é o tempo teórico para produzir uma peça solicitada pelo cliente (GAUTAM et al., 2012); sendo um fator primordial para a sincronização da produção e consiste na disponibilização de uma unidade de produto em conformidade com o intervalo de tempo dentro do qual um produto possa ser vendido (LIMA et al., 2016). Segundo Vieira (2017) o tempo Takt (TT) é definido a partir da demanda do mercado e do tempo disponível para a produção, ou seja, é a frequência em que um produto deve ser produzido com base no ritmo das vendas para atender à demanda dos clientes (ROTHER et al., 2003), resultando da proporção do tempo disponível para produção (capacidade disponível) e do número de unidades a serem produzidas (demanda).

\section{Indicadores}

Para Duque et al. (2007), os indicadores são importantes para monitorar o progresso da implantação Lean, sua efetividade e comparação com o benchmarking. A avaliação de performance tem importância primordial em qualquer atividade e o Lean Manufacturing tem sido aplicado com sucesso pelas organizações para melhorar as operações industriais, garantindo, por meio de sua aplicação, a qualidade, reduzindo os custos e aumentando a pontualidade das entregas (SABOO et al., 2014). Cardoza et al. (2005) afirmam que a manufatura enxuta utiliza indicadores criados a partir das atividades que agregam valor, permitindo assim o constante monitoramento dos os resultados e suas fontes de variação. Consequentemente, os desperdícios podem ser identificados e eliminados.

\section{METODOLOGIA}

O objeto de estudo desse artigo é reavaliar o trabalho padronizado de uma linha de montagem de em uma indústria automotiva da região Sul Fluminense buscando identificar se há desperdícios padronizados, ou se já estamos no estado da arte dessa técnica. Utilizou-se a metodologia de pesquisa-ação, escolhida por ser o método que melhor descreve o envolvimento do pesquisador no processo de pesquisa. A pesquisa-ação é um método de pesquisa qualitativa que cada vez mais se destaca como estratégia de pesquisa (MELLO et al., 2012). Toda pesquisa-ação possui caráter participativo, pelo fato de promover ampla interação entre pesquisadores e membros representativos da situação investigada, pois, caracteriza-se por 
ser um tipo de pesquisa social com base empírica, que é concebida e realizada em estreita associação com uma ação ou com a resolução de um problema coletivo e no qual os pesquisadores e os participantes representativos da situação ou do problema estão envolvidos do modo cooperativo ou participativo (THIOLLENT, 1997). A pesquisa-ação tem uma natureza investigativa devendo ser conduzida em conjunto com aqueles que participam do estudo (MIGUEL, 2011).

Quadro 1: Estruturação da pesquisa-ação x etapas de implantação.

\begin{tabular}{|c|c|c|}
\hline $\begin{array}{l}\text { Estruturação de Thiollent } \\
\text { (2007) }\end{array}$ & Etapas de implantação do Trabalho Padrão & $\begin{array}{l}\text { Elementos textuais da } \\
\text { pesquisa }\end{array}$ \\
\hline $\begin{array}{l}\text { Definir estrutura } \\
\text { conceitual-teórica }\end{array}$ & Fundamentação através do referencial teórico & Revisão teórica \\
\hline Planejar a pesquisa-ação & Definição da linha de estudo e cálculo do Takt & \multirow{4}{*}{ Resultados } \\
\hline Coleta os dados & $\begin{array}{l}\text { Determinar as tarefas repetitivas e levantar os elementos de trabalho } \\
\text { do processo }\end{array}$ & \\
\hline $\begin{array}{l}\text { Analisar os dados e } \\
\text { planejar ações }\end{array}$ & $\begin{array}{l}\text { Reanalisar os elementos e definir uma sequência otimizada para um } \\
\text { novo procedimento operacional }\end{array}$ & \\
\hline Implementar ações & Documentar o procedimento definido & \\
\hline Avaliar o resultado & Verificar os ganhos com a utilização dos procedimentos. & Discussão \\
\hline
\end{tabular}

Fonte: Adaptado de Thiollent (2007).

O quadro 1 relaciona as etapas propostas por Thiollent (2007) com as etapas de reanálise do trabalho padrão para a condução da pesquisa-ação: (1) Planejar a pesquisa-ação; (2) Coletar os dados; (3) Analisar os dados e planejar ações; (4) Implementar ações; e (5) Avaliar o resultado. O propósito da pesquisa-ação é mudar um sistema organizacional ou social particular no qual os participantes estão envolvidos (BALLANTYNE, 2004).

\section{RESULTADOS}

A pesquisa-ação foi conduzida em uma indústria multinacional Alemã que atua em 38 países, emprega aproximadamente 29.400 funcionários em 170 unidades, sendo que sete (7) delas estão no MERCOSUL. A unidade amostrada tem aproximadamente $2000 \mathrm{~m}^{2}$ e está ligada a divisão automotiva do grupo abrigando uma (1) linha de pintura, cinco (5) linhas de solda, uma (1) unidade de usinagem e quatro (4) linhas de montagem, incluindo a linha de suspensão dianteira, foco da pesquisa-ação.

Neste trabalho seguiram-se as etapas do método de pesquisa-ação de Thiollent (2007), adaptado para a reanálise do trabalho padrão, onde: (1) Realização da fundamentação. Etapa realizada através do referencial teórico; (2) Definição da linha de estudo e cálculo do Takt; (3) Determinar as tarefas repetitivas e levantar os elementos de trabalho do processo inicial; (4) Reanalisar os elementos que não agregam valor e definir uma sequência otimizada para um novo procedimento operacional; (5) Documentar o procedimento definido e (6) Verificar os ganhos com a utilização dos procedimentos.

\section{Definição da linha de estudo e cálculo do Takt}

Para facilitar a comparação entre a situação da linha antes do início da pesquisa e após a conclusão da reanálise do trabalho padronizado na linha de módulos de suspensão dianteira, descreve-se o cenário encontrado ao diagnosticar a situação inicial. Essa linha trabalhava em três turnos, seis (6) dias por semana, 
onde onze (11) operadores executam a montagem do produto final na linha. Os indicadores de qualidade e segurança não demostravam nenhum desvio.

A linha operava no sistema Just in Sincron e montava uma variedade de modelos fabricados de acordo com uma sequência determinada pelo cliente e recebida pela linha através de um sistema de troca de eletrônica de dados (EDI-Exchange Data Information). A demanda diária atendida pela linha era de 950 carros por dia, como o takt de 91 segundos, e o processo de fabricação se completava após quatorze (14) operações, das quais doze (12) eram operações de montagem e duas (2) eram apenas inspeções. Levando em conta a eficiência da linha, definiu-se o tempo objetivo para alocação das atividades em $90 \%$ do tempo takt, para não colocar em risco o atendimento ao cliente devido a eficiência da produção (OEE) representando uma taxa global de eficiência dos equipamentos (FERREIRA et al., 2012).

\section{Determinar as tarefas repetitivas e levantar os elementos de trabalho do processo inicial}

Partindo-se do objetivo de reavaliar o trabalho padronizado do processo produtivo de uma linha de montagem e entender se há oportunidade de melhoria, determinaram-se os elementos de trabalho e os descreveu na folha de operações da linha (FEP) gerando os dados necessários para a fase de preparação do estudo. Na etapa de tomada dos tempos foram obtidos dados uteis para a busca de oportunidades no processo. Coletaram-se em cada um dos três turnos, cinco (5) vezes o tempo de operação de cada atividade, totalizando quinze (15) tempos para cada elemento de trabalho. Registraram-se os tempos coletados na FEP (folha de estudos do processo - Figura 1).

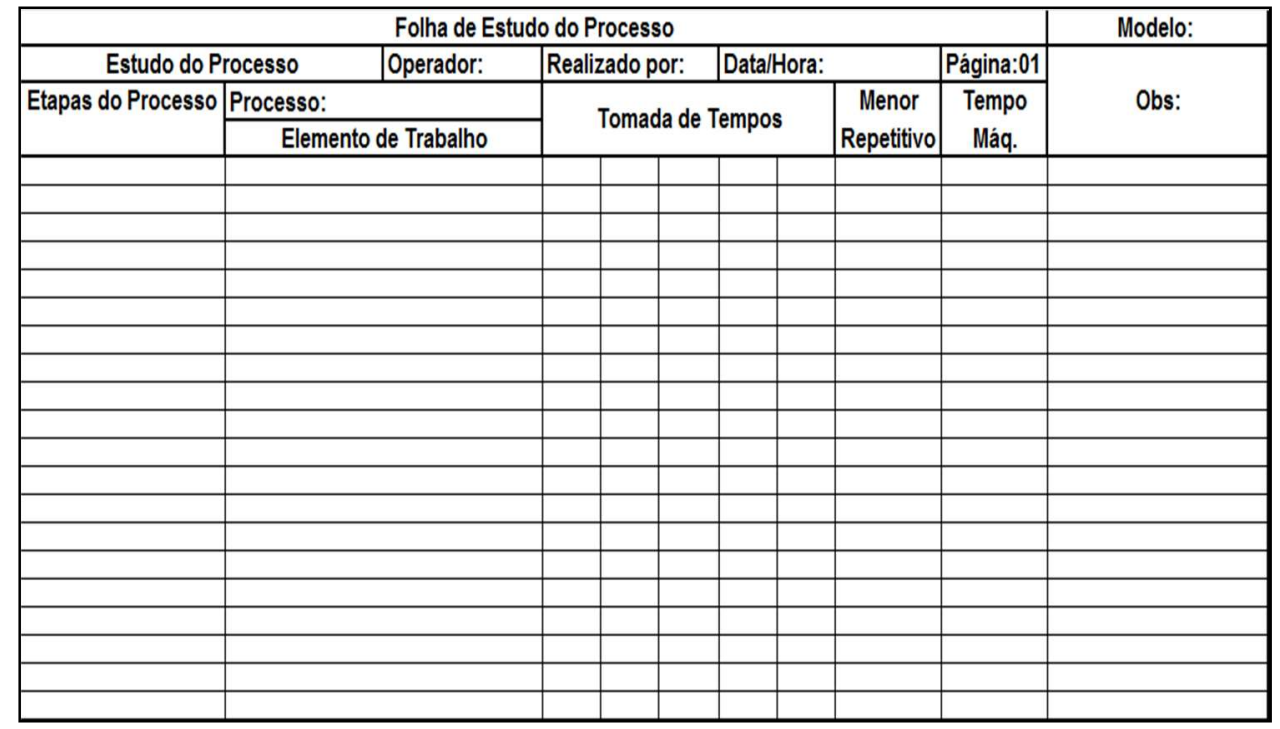

Figura 1: Exemplo de FEP (folha de estudos de processo).

Para padronização das atividades e definição da carga de trabalho de cada operador, o primeiro passo foi revisar o tempo padrão da atividade, sendo que para a pesquisa considerou-se o menor tempo repetido coletado na FEP. Utilizou-se esse tempo por se entender que, uma vez que se repetia ele era um tempo possível, mas nos casos em que o menor tempo repetido se distanciava da média de outro turno, como por exemplo, o operador do turno 1 executava as atividades da operação 'A' em 30 segundos e o do turno '2' executava essas mesmas atividades em 110 segundos, padronizava-se a prática utilizada pelo 
colaborador do turno '1' utilizando sua experiência e metodologia e através de um treinamento estendeu-se esse conhecimento para os outros turnos.

Para a reanálise do trabalho padrão usou-se três categorias: agrega valor ao cliente: essas atividades devem ser mantidas e se possível melhoradas, como por exemplo a montagem de um componente no produto; não agrega valor ao cliente, mas é uma atividade inevitável: essas atividades devem ser reduzidas ao máximo possível, como por exemplo a transferência de um subconjunto do equipamento ' $A$ ' para o equipamento 'B'; não agrega valor ao cliente e é um desperdício que pode ser eliminado: essas atividades não devem ser mantidas, como por exemplo, colocar um subconjunto em uma mesa e depois retirá-lo sem que o produto tenha sofrido qualquer agregação de valor.

\section{Reanalisar os elementos e definir uma sequência otimizada para um novo procedimento operacional}

A gestão visual do trabalho padronizado informa de modo completo e preciso o balanceamento dos postos, indicando a presença das conexões de informação, permitindo que os operadores conheçam os postos críticos, a quantidade de peças entre operações, o ritmo de produção de cada operador e do processo cliente (MARODIN et al., 2013). Essa gestão visual foi evidenciada também na reanálise do trabalho, pois, seguindo a necessidade real do cliente (Takt), foi possível entender os desperdícios padronizados e redistribuir os elementos de trabalho que realmente agregam valor ou eram inerentes ao processo até que estivessem próximo do objetivo de $90 \%$ do Takt. Essa fase contou com a colaboração de operadores e líderes de produção, pois o conhecimento técnico operacional foi de suma importância para a coerência da distribuição das atividades, principalmente quando os elementos de trabalho precisavam ser transferidos de uma operação para outra. Segundo Gonzalez et al. (2014), os colaboradores por entender o processo, sugerem as ações importantes. Tendo realizadas todas estas mudanças no processo, um novo balanceamento foi determinado, onde nos gráficos a seguir estão representadas as diferenças entre a distribuição do trabalho antes e após a reanálise do trabalho padrão.

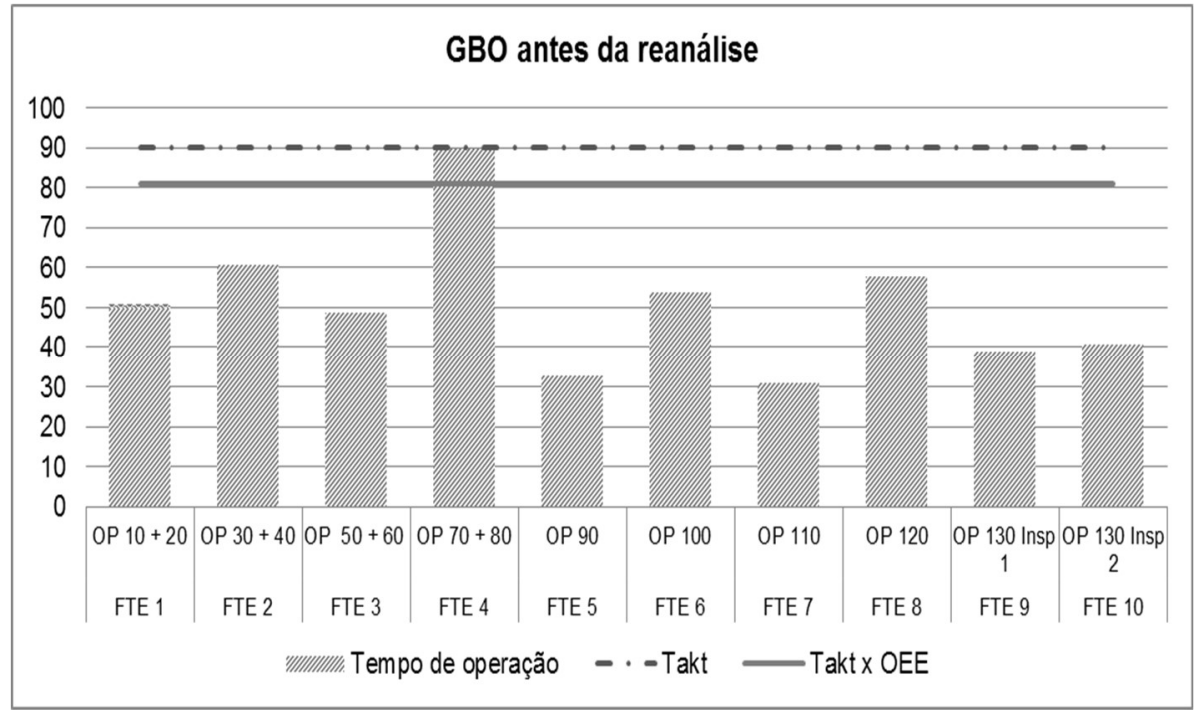

Gráfico 1: Balanceamento da linha antes do trabalho padrão. 


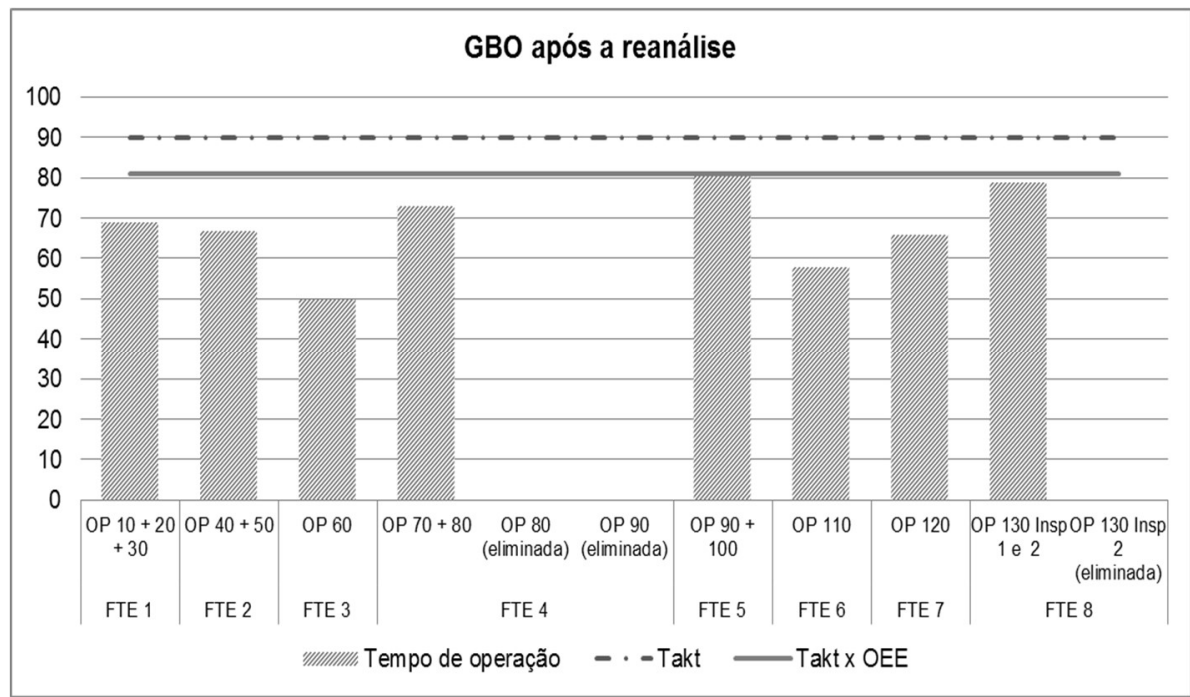

Gráfico 2 - Balanceamento da linha após o trabalho padrão.

\section{Documentar o procedimento definido}

O gráfico 2 apresenta os tempos ciclos alcançados após o balanceamento das operações (GBO), evidenciando algumas lacunas entre o tempo objetivo e o tempo possível, causado pelas limitações técnicas que impediram um resultado ainda mais expressivo.

As operações ficaram da seguinte forma: colaborador 1- responsável por fazer as operações 10, 20 e 30 que assumiu alguns elementos de trabalho da operação 40; colaborador 2- responsável por fazer as operações 40 e 50 que assumiram alguns elementos de trabalho da operação 80 . Ressalta-se aqui, que vários elementos de trabalho da operação 40 foram eliminados, pois não agregavam valor para o processo; colaborador 3- responsável por fazer a operação 60, a qual assumiu alguns elementos de trabalho da operação 80; colaborador 4- responsável por fazer as operações 70 e 80 que foram unificadas com a eliminação da bancada da operação 80; colaborador 5- assumiu todos os elementos de trabalho da operação 90 e continuou responsável pela operação 100. Nessa operação o tempo objetivo foi ultrapassado em dois segundos, porém por se tratar de uma operação com uma confiabilidade alta, a equipe decidiu manter esse tempo ciclo; colaboradores 6 e 7- continuaram com suas respectivas atividades e assumiram algumas inspeções que eram realizadas no segundo posto de controle (inspeção 2) da operação 130; colaborador 8assumiu as inspeções restantes da inspeção 2 da operação 130 e a retirada de todos os componentes e disposição na embalagem final de entrega ao cliente. Para essa operação foi necessária uma alteração na assistência (manipulador) para que possibilitasse o manuseio do produto acabado, anteriormente efetuada do lado oposto.

\section{DISCUSSÃO}

O trabalho padronizado é um dos pilares do sistema Lean. A qualidade do produto final e a segurança são influenciadas pelo correto seguimento de seus elementos de trabalho e para isso todos os operadores devem conhecer a sequência exata descrita nos documentos do processo. Diante dos dados expostos nos 
gráficos 3 e 4, nota-se que os indicadores de qualidade e segurança se mantiveram estáveis, mesmo após a modificação do trabalho padronizado.

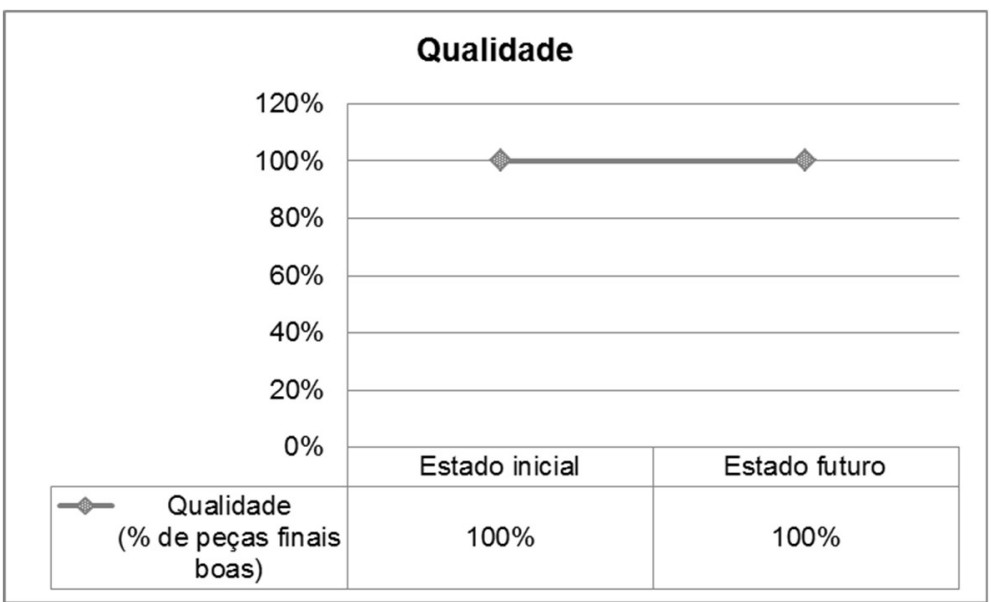

Gráfico 3: Qualidade da linha após o trabalho padrão.

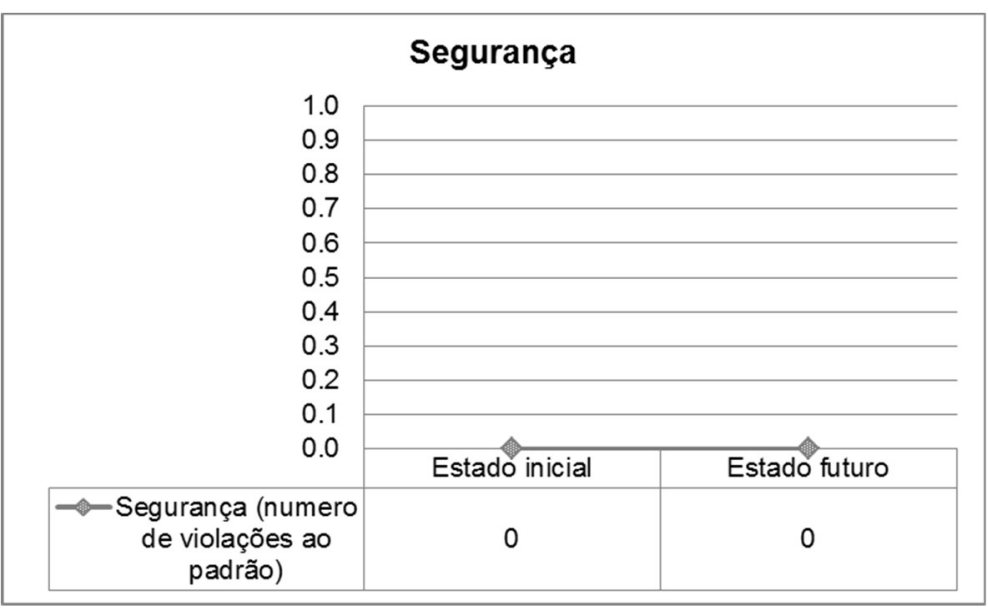

Gráfico 4: Qualidade da linha após o trabalho padrão.

Com a eliminação dos desperdícios e reorganização do trabalho foi possível reduzir dois operadores no processo produtivo da linha estudada, passando de dez para oito operadores, evidenciando que haviam desperdícios padronizados no processo.

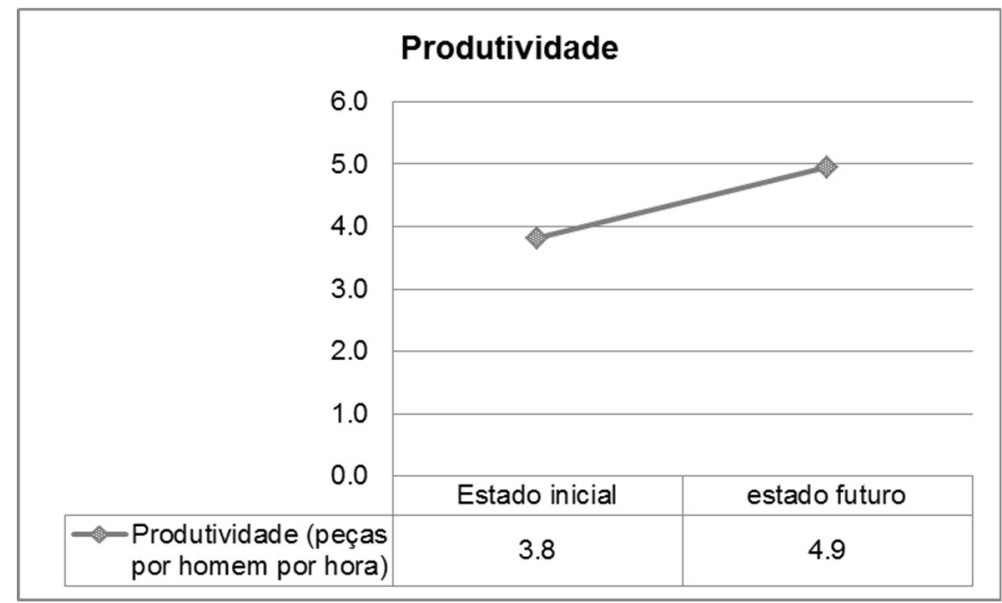

Gráfico 5: Produtividade da linha após o trabalho padrão. 
Constata-se ainda que o indicador de produtividade aumentou mais de $29 \%$, passando de 3.8 para 4.9 peças produzidas por homem a cada hora. Esse acréscimo é o resultado da redução de mão-de-obra direta e a redução de horas extras que deixaram de ser necessárias após a reanálise do trabalho padronizado.

\section{CONCLUSÕES}

O trabalho apresenta a reanálise das atividades padronizadas, investigando um processo produtivo de uma indústria de autopeças estruturada por meio da reanálise do trabalho padronizado e sistematicamente suportado por uma pesquisa-ação. Apesar da aplicação do trabalho padronizado em células de manufatura ser bastante difundido, a investigação proposta pelo objetivo da pesquisa demostrou uma melhora significativa no desempenho operacional do indicador de produtividade, obtendo um acréscimo total de $29 \%$ referente à redução da força de trabalho, resultantes da identificação de atividades padronizadas que não agregavam valor, além de manter os níveis de qualidade e segurança do processo, contrapondo a ideia que essa técnica já está em seu estado da arte. A partir dessa constatação, atinge-se o objetivo de pesquisa, pois, verifica-se que a reanálise do trabalho padronizado corrobora com a afirmativa que as empresas padronizam desperdícios e que é necessário a reavaliação frequente dos processos.

Quanto à contribuição do estudo comprovou-se que a reanálise do trabalho padronizado tem uma influência direta na vantagem competitiva dentro da empresa, porém, como limitação é necessário ressaltar que o projeto representa a realidade de um processo de montagem de uma empresa do setor automotivo, na qual, a linha já estava estabilizada quanto aos critérios de qualidade e segurança, além de já aplicar diversas técnicas de Manufatura Enxuta. Os autores sugerem como uma oportunidade de pesquisa, identificar a quantidade de valor não agregado nas operações em diferentes empresas que aplicam o trabalho padronizado e investigar os fatores que garantem a resiliência dos índices de qualidade e segurança na linha estudada.

\section{REFERÊNCIAS}

ALVES, J. A. C.; SILVA, I. B.. Implantação de conceitos de Manufatura Enxuta em célula de conformação de chapas. GEPROS-Gestão da Produção, Operações e Sistemas, v.5, n.1, p.79-91, 2010.

AZZAM, S. R.; ARIAS, L. C.; ZHOU, S.. Managing a Manufacturing System with Integration of Walking Worker and Lean Thinking. World Academy of Science, Engineering and Technology, Londres, v.55, p.618-620, 2011.

BALLANTYNE, D.. Action research reviewed: a market oriented approach. European Journal of Marketing, v.38, n.4, p.321-337, 2004.

BERKENBROCK, T.; RENÓ, G. W. S.; MARTINS, A. A.; SEVEGNANI, G.; FISCHER, D. A.. Estudo do trabalho padrão em linhas de montagem de refrigeradores. In: ENEGEP. Anais. 2009.

BHAMU, J.; SANGWAN, K. S.. Lean manufacturing: literature review and research issues. International Journal of
Operations \& Production Management, v.34, n.7, p.876940, 2014. DOI: http://dx.doi.org/doi:10.1108/IJOPM-08-2012-0315

BULHÕES, I. R.; PICCHI, F. A.. Diretrizes para a implementação de fluxo contínuo em obras de edificações. Ambiente Construído, v.11, n.4, p.205-223, 2011.

CANÇADO, V. L.; SANTOS, T. M. C.. Reação à mudança organizacional: A implementação do Lean Thinking na Empresa Beta. Revista Gestão \& Tecnologia, v.14, n.1, p.100-125, 2014. DOI: http://10.20397/g\&t.v14i1.592

CARDOZA, E.; CARPINETTI, L. C. R.. Indicadores de desempenho para o sistema de produção enxuto. Revista Produção Online, v.5, n.2, p.1676-1901, 2005.

CASTRO, F. P.; ARAUJO, F. O.. Proposal for OEE (Overall Equipment Effectiveness) Indicator Deployment in a Beverage Plant. Brazilian Journal of Operations \& Production Management v.9, n.1, p.71-84, 2012. DOI: http://dx.doi.org/10.4322/bjopm.2013.006 
DEMETER, K.; MATYUSZ, Z.. The impact of lean practices on inventory turnover. International Journal Production Economics, v.133, p.154-163, 2011. DOI: http://dx.doi.org/10.1016/j.ijpe.2009.10.031

DUQUE, D. F. M.; CADAVID, L. R.. Lean Manufacturing measurement: the relationship between lean activities and lean metrics. Estudios gerenciales, v.23, n.105, p.69-83, 2007. DOI: http://dx.doi.org/10.1016/S0123-5923(07)700268

FERREIRA, C. C.; CETNARSKI, E. M.; SALDANHA, G. C.; COSTA, S. E. G.; EDSON, E. P.. Consequências da implantação pontual de ferramentas Lean. Journal of lean systems, v.1, n.1, p 5166, 2016.

FERREIRA, T.; MOREIRA, D.; DISCONZI, C.. Análise da Produtividade de Uma Empresa de Beneficiamento de Arroz Através do Índice de Rendimento Global. In: ENCONTRO NACIONAL DE ENGENHARIA DE PRODUÇÃO, 32. Anais. Bento Gonçalves: ABEPRO, 2012.

FILHO, M. G.; CAMPOS, F. C.; ASSUMPÇÃO, M. R. P.. Revisão sistemática da literatura com análise bibliométrica sobre estratégia e Manufatura Enxuta em segmentos da indústria. Gestão \& Produção, v.23, n.2, p.408-418, 2016. DOI: http://dx.doi.org/10.1590/0104-530X1683-14

FLINCHBAUGH, J.. The need for training within industry: standard work is one of the most challenging aspects of a lean transformation. Industry Week, v.264, n.5, p.10, 2015.

FREITAS, E. S.; SILVA, M. G.. Pesquisa-ação sobre a implementação do trabalho padronizado em uma célula de manufatura de uma fábrica de tratores. ESPACIOS, v.38, n.46, p.21, 2017.

GAUTAM, R.; KUMAR, S. I.; SINGH, S.. Kaizen Implementation in an Industry in India: A Case Study. International Journal of Research in Mechanical Engineering \& Technology, v.2, n.1, p.25-33, 2012.

GONZALEZ, R. V. D.; MARTINS, M. F.. Knowledge Management: An Analysis From the Organizational Development. Journal of Technology Management \& Innovation, v.9, n.1, p.131-147, 2014.

JOHANSSON, P. E. C.; LEZAMA, T.; MALMSKÖLD, L.; SJÖGREN, B.; AHLSTRÖM L. M.. Current State of Standardized Work in Automotive Industry in Sweden. Procedia CIRP, v. 7, p.151-156, 2013. DOI: https://doi.org/10.1016/j.procir.2013.05.026

LEITE, M. S.; SANTOS, S. C.; SILVA, A. M.; FERREIRA, W. P.. Eficácia da heurística da utilização incremental para balanceamento de linha: Estudo de caso em um processo de tratamento de superfície. Revista Produção Online, v.17, n.3, p.781-803, 2017.

LIKER, J. K.. O Modelo Toyota: 14 Princípios de Gestão do Maior Fabricante do Mundo. Porto Alegre: Bookman, 2005.

LIMA, D. F. S.; ALCANTARA, P. G. F.; SANTOS, L. C.; SILVA, L. M. F.; SILVA, R. M.. Mapeamento do fluxo de valor e simulação para implementa. Revista Produção Online, v.16, n.1, p.366-392, 2016. DOI: http://dx.doi.org/10.14488/16761901.v16i1.2183

MARIZ, R. N.; PICCHI, F. A.. Método para aplicação do trabalho padronizado. Ambiente Construído, v.13, n.3, p.727, 2013. DOI: http://dx.doi.org/10.1590/S1678$\underline{86212013000300002}$

MARODIN, G.; SAURIN, T. A.. A influência das práticas de produção enxuta nos atributos qualificadores das células de manufatura. Revista Produção Online, v.13, n.4, p.12521275, 2013. DOI: http://dx.doi.org/10.14488/16761901.v13i4.1207

MELLO, C. H. P.; TURRIONI, J. B.; XAVIER, A. F.; CAMPOS, D. F.. Pesquisa-ação na engenharia de produção: proposta de estruturação para sua condução. Revista Produção Online, v.22, n1, p. 1-13, 2012. DOI: http://dx.doi.org/10.1590/S0103-65132011005000056

MIGUEL, P. C.. Aspectos relevantes no uso da pesquisa-ação na engenharia de produção. Exacta, v. 9, n.1, p.59-70, 2011.

NEGRÃO, L. L.; MONTEIRO, M. A. M.; RAMOS, M. O.; GONÇALVES, M. C.; DIAS, I. C. P.. Avaliação da relação entre a importância e desempenho de práticas de lean manufacturing em um centro de distribuição. Journal of lean systems, v.1, n.4, p.87-11, 2016. DOI: http://ojs.sites.ufsc.br/index.php/lean 87

NETO, D. A. C.; FARIA, A. C.; SILVA, I. B.. Proposta de utilização do pensamento enxuto em um laboratório de controle biológico. In: SIMPOI. Anais. 2015.

RAJENTHIRAKUMAR, D.; SRIDHAR, R.. Development of lean assembly line: a case study. International Journal of Lean Thinking, v.5, n.1, p.1-8, 2014.

ROTHER, M.; SHOOK, J.. Aprendendo a enxergar: Mapeando o Fluxo de Valor para Agregar Valor e Eliminar o Desperdício. São Paulo: Lean Institute Brazil, 2003.

SABOO, A.; GARZA-REYES, L. A.; ER. A.; KUMAR, V.. A VSM improvement-based approach for lean operations in an Indian manufacturing SME. Int. J. Lean Enterprise Research, v.1, n.1, p.41-58, 2014.

SANTOS, L. C.; GOHR, C. F.; GONÇALVES, J. M. S.; VILAR, F. M. M.; ARNAUD, L. M.. Identificação e avaliação de práticas de produção enxuta em empresas calçadistas do estado da Paraíba. Revista Produção Online. v. 17, n. 1, p. 176-199, 2017. DOI: http://dx.doi.org/10.14488/16761901.v17i1.2403

SAURIN, T. A.; RIBEIRO, J. L. D.; MARODIN, G. M. Identificação das oportunidades de pesquisa a partir de um levantamento da implantação da produção enxuta em empresas do Brasil e do exterior. Gestão da Produção, v.17, n.4, p.829-841, 2010.

SHINGO, S.. O Sistema Toyota de Produção: do ponto de vista da engenharia de produção. Porto Alegre: Bookman, 1996.

SILVA, E. H. D. R. S.; LIMA, E. P. L.; COSTA, S. E. G.. Qual o significado de valor? Uma abordagem baseada em diferentes perspectivas. Revista Produção Online, v.15, n.4, 
p.1326-1350, 2015. DOI: http://dx.doi.org/10.14488/16761901.v15i4.1915

SILVA, I. B.; MIYAKE, D. I.; BATOCCHIO, A.; AGOSTINHO, O. L.. Integrando a promoção das metodologias Lean

Manufacturing e Six Sigma na busca de produtividade e qualidade numa empresa fabricante de autopeças. Gestão e Produção, v.18, n.4, p.687-704, 2011.

SILVA, I.; XAMBRE, A. R; LOPES, R. B.. A Simulation Game Framework for Teaching Lean Production. International Journal of Industrial Engineering and Management, v.4, n.2, p.81-86, 2013.

THIOLLENT, M.. Pesquisa-ação nas organizações. São Paulo: Atlas, 1997.
TORTORELLA, L. G.; FETTERMANN, D.; ANZANELLO, M.

Implementação da manufatura enxuta e os comportamentos das lideranças: uma pesquisa exploratória. Revista Produção Online. v.17, n. 3, p. 857-882, 2017. DOI: https://doi.org/10.14488/1676-1901.v17i3.2675

TORTORELLA, L. G.; FOGLIATTO, F, S.. Assessment of organizational maturity for lean change. Sistemas \& Gestão, v.8 p.444-451, 2013. DOI:

http://doi.org/10.7177/sg.2013.v8.n4.a10

VIEIRA, E. L.. Signatures factory: a dynamic alternative for teaching - learning layout concepts and waste disposal.

Production, v.27, p.1-14, 2017. DOI:

http://dx.doi.org/10.1590/0103-6513.221716

A CBPC - Companhia Brasileira de Produção Científica (CNPJ: 11.221.422/0001-03) detém os direitos materiais desta publicação. Os direitos referem-se à publicação do trabalho em qualquer parte do mundo, incluindo os direitos às renovações, expansões e disseminações da contribuição, bem como outros direitos subsidiários. Todos os trabalhos publicados eletronicamente poderão posteriormente ser publicados em coletâneas impressas sob coordenação da Sustenere Publishing, da Companhia Brasileira de Produção Científica e seus parceiros autorizados. Os (as) autores (as) preservam os direitos autorais, mas não têm permissão para a publicação da contribuição em outro meio, impresso ou digital, em português ou em tradução. 